\title{
Primary Ewing's Sarcoma of Frontoparietal Bone with Major Soft Tissue Extension: An Unusual Presentation and Review of the Literature
}

\author{
Anshu Gupta, Sachin Bansal, and Sujata Chaturvedi \\ Department of Pathology, Institute of Human Behavior and Allied Sciences, Dilshad Garden, Delhi 95, India \\ Correspondence should be addressed to Anshu Gupta, dransh2002@yahoo.co.in \\ Received 28 May 2012; Accepted 7 August 2012 \\ Academic Editors: K. Aozasa and A. Rajput
}

Copyright () 2012 Anshu Gupta et al. This is an open access article distributed under the Creative Commons Attribution License, which permits unrestricted use, distribution, and reproduction in any medium, provided the original work is properly cited.

\begin{abstract}
An 11-year-old girl presented with progressively increasing swelling in scalp of 8-month duration with no neurological deficit. Local examination showed a hard swelling that seemed to be arising from frontal bone. General and systemic examination was normal. MRI revealed a well-defined lytic lesion in left frontoparietal bone with a subgaleal component. The patient was operated upon and excision of tumor with reconstruction of skull was done. Histopathological examination showed a monomorphic small round cell tumor of bone infiltrating into the subcutaneous tissue. Immunohistochemical stain showed diffuse immunopositivity for MIC-2 in tumor cells, thus final diagnosis of Ewing's sarcoma was made. The patient was kept for follow up for 3 months and had no symptoms.
\end{abstract}

\section{Introduction}

Ewing's sarcoma is most commonly seen in children and young adults with a peak incidence in the second decade of life. It most commonly arises in long bones of the extremities (predominantly femur) and pelvis [1]. Primary Ewing's sarcoma of the cranial bone is rare and contributes about $1 \%$ of all Ewing's sarcoma [2]. Temporal bone is most commonly affected followed by frontal and parietal bone [3]. Considering its unusual site and soft tissue extension, we report a case of Primary Ewing's sarcoma of frontoparietal bone with soft tissue extension.

\section{Case Report}

An 11-year-old girl presented with painless swelling in left frontoparietal region of scalp from 8 months and progressively increasing in size. The mass was detected incidentally when she had a fall. There was no history of headache, vomiting, fever, and seizure or any focal neurological deficit. Local examination revealed a hard mass of $50 \times 48 \mathrm{~mm}$ in size with normal overlying skin. She has no sensory and motor deficit. Her general and systemic examination was normal.
Blood investigations were normal. CT scan shows a welldefined lytic lesion in left frontoparietal bone. On MRI, a lytic lesion in left frontoparietal calvarium was seen with sun ray periosteal reaction, measuring $60 \times 53 \mathrm{~mm}$ in size with a subgaleal and epidural component causing bulking of parenchyma (Figure 1). The patient was operated and excision of left frontal tumor with reconstruction of skull was done. Intraoperative frozen section revealed monomorphic small round cells arranged in clusters and scattered singly. Diagnosis of a malignant round cell tumor was made.

The tumor was sent for histopathological examination. Grossly, the specimen consists of one large grayish brown soft tissue attached to a flat bony fragment measuring $7.0 \times 7.0 \times$ $4.5 \mathrm{cms}$. External surface of the soft tissue was smooth and partially encapsulated. Cut surface of the soft tissue was gray white to yellowish gelatinous and showed few hemorrhagic areas also (Figure 2). On microscopic examination, section revealed a monomorphic round cell tumor arranged in lobular, trabecular, and micro- and macrofollicular pattern with eosinophilic secretion in the lumen (Figure 3). Tumor cells had round nuclei with stippled chromatin, prominent nucleoli, and thick nuclear membrane. Cytoplasm was moderate in amount and vacuolated. Connective tissue 


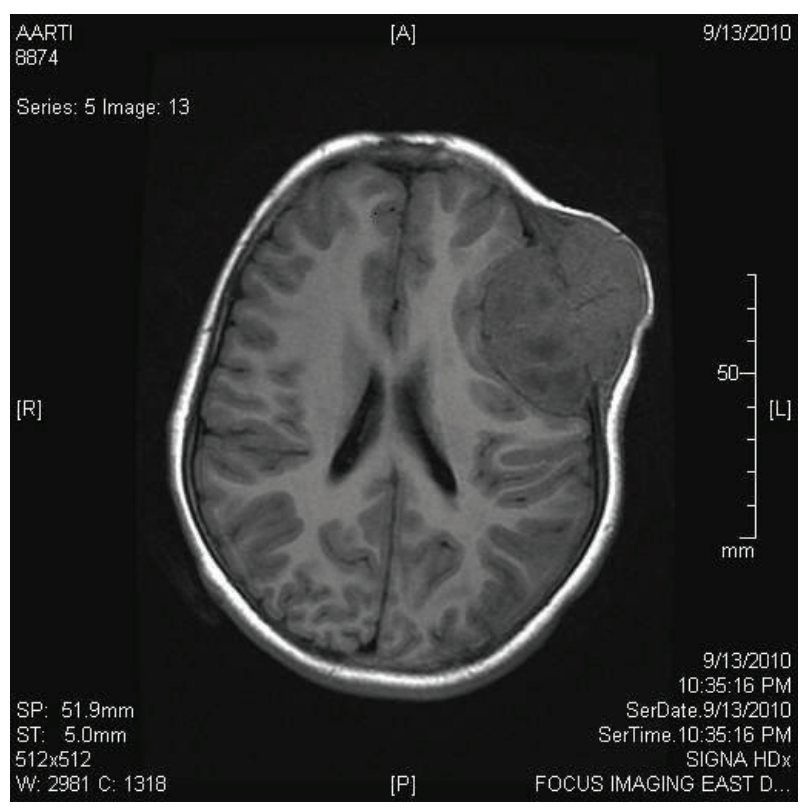

FIgure 1: Postcontrast T1 weighted MRI showed intense, homogenously enhancing intracranial mass causing destruction of bone, with extradural soft tissue extension.

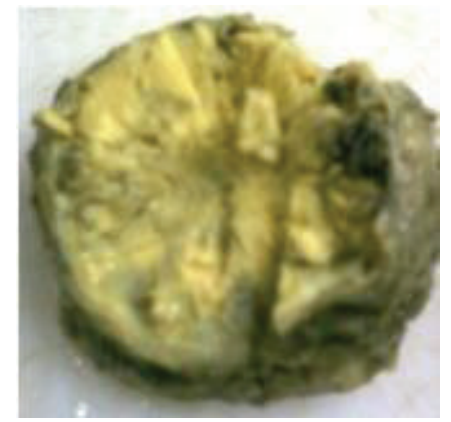

FIGURE 2: Gross specimen revealing well-circumscribed tumor with gray white to yellow gelatinous cut surface.

septae with fine blood vessels were seen throughout the tumor. Mitosis was $0-2 / \mathrm{hpf}$. There was also infiltration of tumor cells in the surrounding fibroadipose tissue. Section examined from bone showed bony trabeculae and bone marrow revealing marked fibrosis and infiltration by tumor cells. On Periodic Acid Schiff (PAS) stain, tumor cells were negative. On immunohistochemistry, tumor cells were immunopositive for MIC-2. Keeping in view the morphological and immunohistochemical profile, a final diagnosis of Ewing's sarcoma of bone was made.

\section{Discussion}

Ewing's sarcoma involving the skull is rare and occurs in less than $1 \%$ of cases [2]. Commonest site of Primary Ewing's sarcoma is temporal bone followed by parietal and occipital bone. Sphenoid and ethmoid bones are less commonly

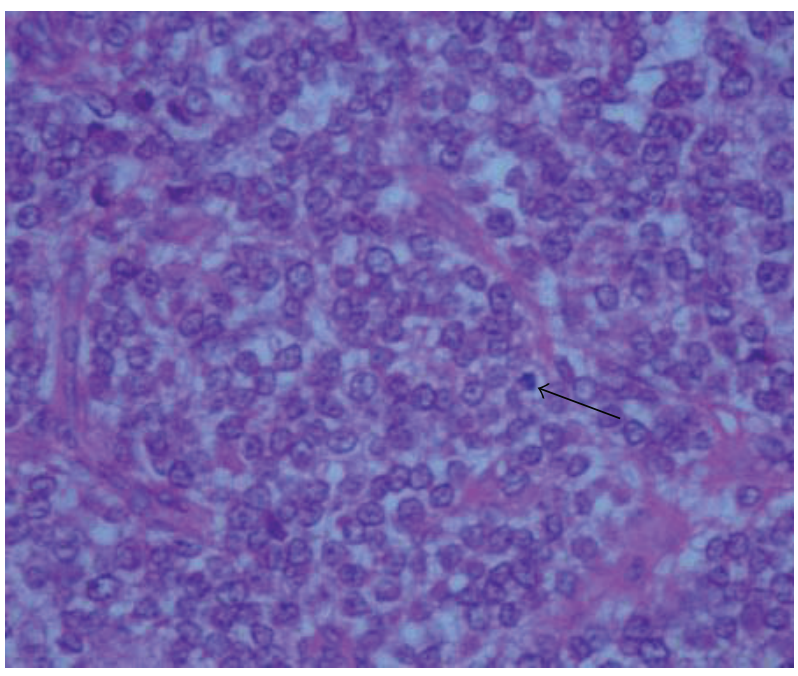

FIGURE 3: Microsection showing lobular arrangement of malignant round tumor cells with abundant vacuolated cytoplasm. Atypical mitosis also seen. Haematoxylin and Eosin $(\mathrm{H} \& \mathrm{E})$ stain $\times 40 \mathrm{x}$.

involved [3]. In published cases of Primary Ewing's sarcoma of the cranium, the most common symptoms reported at the time of diagnosis have been local swelling (as in our case) and associated headache. Patient with the skull base as the primary site may present with proptosis and various types of cranial nerve palsy. When there is, intracranial extension or involvement of neural structures there may be features of raised intracranial pressure as well as focal neurological deficit [4]. In our case there is no focal neurological deficit.

On plain X-ray many patients may show areas of bone destruction as in our case, with irregular poorly defined margin. The most common CT finding is isodense lesion with marked heterogenous enhancement. Biopsy is essential for definitive diagnosis. In our case, the histological diagnosis is made by examining the morphology and immunohistochemical profile of tumor cells [5].

The main differential diagnosis of tumor involving the skull with adjacent soft tissue extension in children would include metastatic neuroblastoma, PNET, chordoma, and lymphoma. Less common differential diagnosis includes rhabdomyosarcoma, osteosarcoma, meningioma, Langerhan's cell histiocytosis, desmoplastic small round cell tumor, plasmacytoma, and solitary metastasis. The differentiation between these may not be possible on light microscopy and require special stains and immunohistochemistry for final diagnosis. Although cytoplasmic glycogen content was considered to be important in differential diagnosis, in specimen fixed in formalin and embedded in paraffin, the glycogen may not be always demonstrated with PAS staining as in our case [6].

Primitive neuroectodermal tumor expresses neuronal marker such as synaptophysin, neurofilament protein, nonspecific enolase or S-100. Lymphoma cells express $\mathrm{CD}_{19}$, $\mathrm{CD}_{20}$, and $\mathrm{CD}_{2,5,8}$. Chordoma express strong positivity for Pan CK and Epithelial membrane antigen [5]. MIC-2 is aspecific marker for Ewing's sarcoma and peripheral primtive neuroectodermal tumors [7]. 
Immunopositivity for MIC-2 confirmed the diagnosis in our case.

Early diagnosis and treatment prior to metastasis is essential for long-term survival in patient with Ewing sarcoma. The disease is treated through multidisciplinary approach that includes surgery, chemotherapy, and radiotherapy. This patient was kept for follow up and had no symptoms. In conclusion, primary cranial Ewing's sarcoma is to be considered in the differential diagnosis in children with a tumor involving the skull with destruction of bone and the presence of extra axial soft tissue involvement. Primary Ewing's sarcoma is reported to have a better prognosis as compared to Ewing's sarcoma elsewhere.

\section{References}

[1] K. K. Unni, “Ewing's tumor," in Dahlin's Bone Tumors: General Aspects and Data on 11087 Cases, K. K. Unni, Ed., pp. 249-261, Lippincott-Raven, Philadelphia, Pa, USA, 5th edition, 1996.

[2] P. Steinbok, F. lodmark O, M. G. Norman, C. han KW, and C. J. Fryer, "Primary Ewing's sarcoma of the base of skull," Neurosurgery, vol. 19, no. 1, pp. 104-107, 1986.

[3] P. Singh, M. Jain, D. P. Singh, N. Kalra, N. Khandelwal, and S. Suri, "MR findings of primary Ewing's sarcoma of greater wing of sphenoid," Australasian Radiology, vol. 46, no. 4, pp. 409411, 2002.

[4] K. I. Desai, T. D. Nadkarni, A. Goel, D. P. Muzumdar, K. N. Naresh, and C. N. Nair, "Primary Ewing's sarcoma of the cranium," Neurosurgery, vol. 46, no. 1, pp. 62-69, 2000.

[5] D. Schmidt, D. Harms, and V. A. Pilon, "Small-cell pediatric tumors: histology, immunohistochemistry, and electron microscopy," Clinics in Laboratory Medicine, vol. 7, no. 1, pp. 63-89, 1987.

[6] F. H. Sim, K. K. Unni, J. W. Beabout, and D. C. Dahlin, "Osteosarcoma with small cells simulating Ewing's tumor," Journal of Bone and Joint Surgery A, vol. 61, no. 2, pp. 207-215, 1979.

[7] I. M. Ambros, P. F. Ambros, S. Strehl, H. Kovar, H. Gadner, and M. Salzer-Kuntschik, "MIC2 is a specific marker for Ewing's sarcoma and peripheral primitive neuroectodermal tumors: evidence for a common histogenesis of Ewing's sarcoma and peripheral primitive neuroectodermal tumors from MIC2 expression and specific chromosome aberration," Cancer, vol. 67, no. 7, pp. 1886-1893, 1991. 


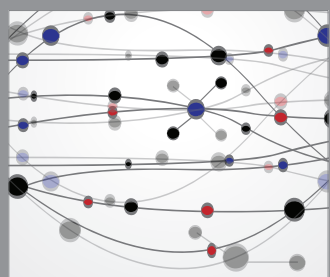

The Scientific World Journal
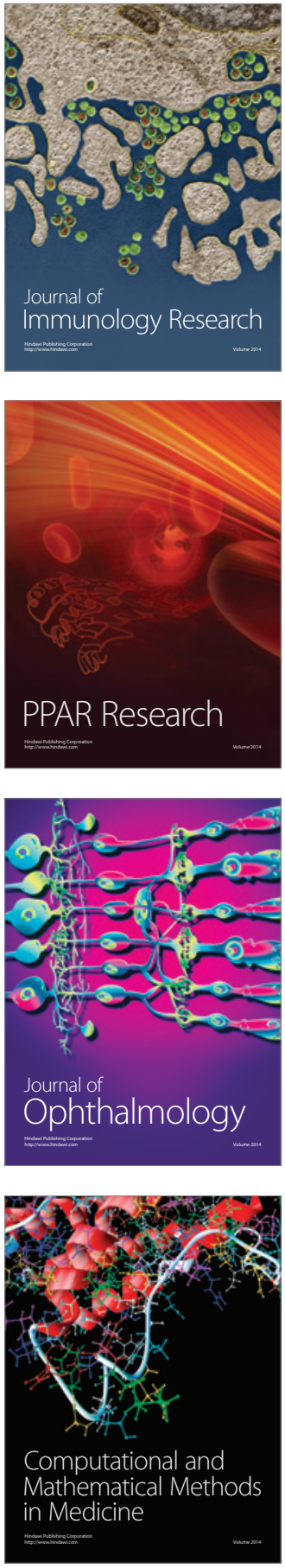

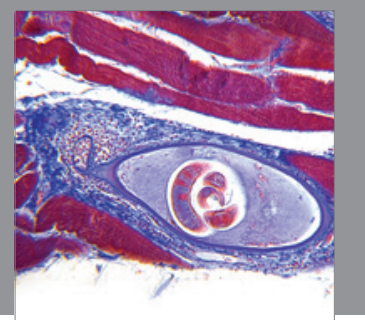

Gastroenterology

Research and Practice
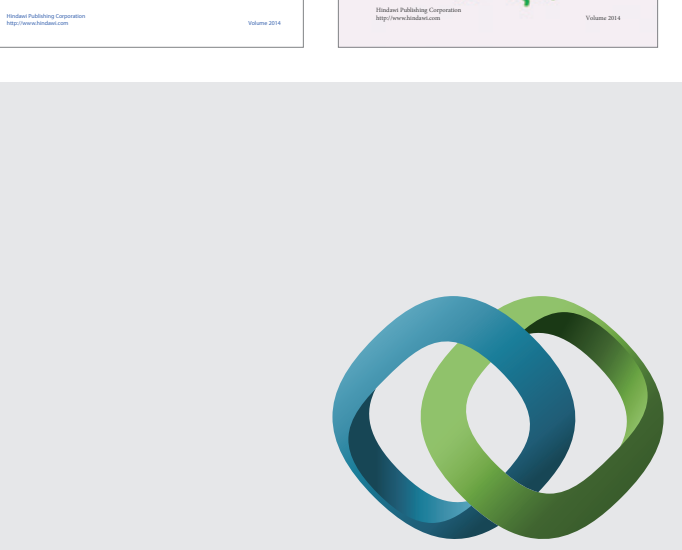

\section{Hindawi}

Submit your manuscripts at

http://www.hindawi.com
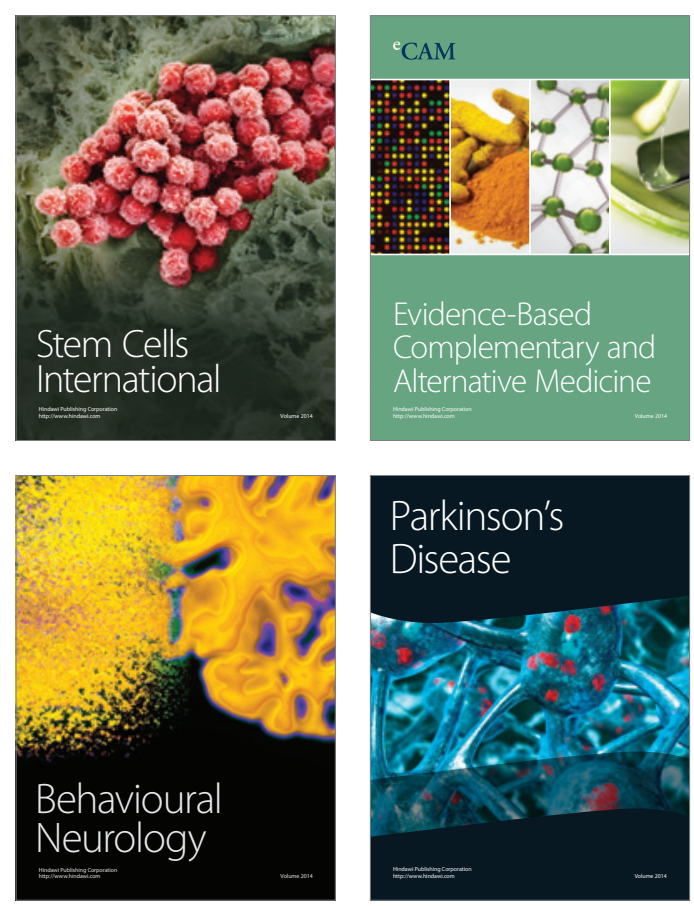

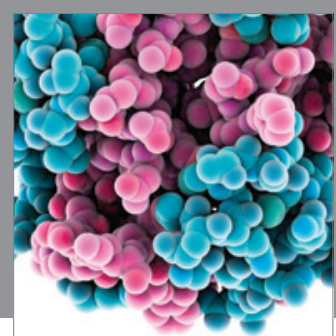

Journal of
Diabetes Research

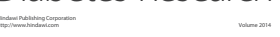

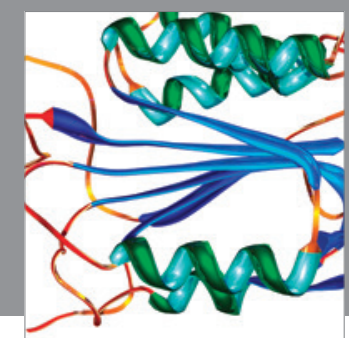

Disease Markers
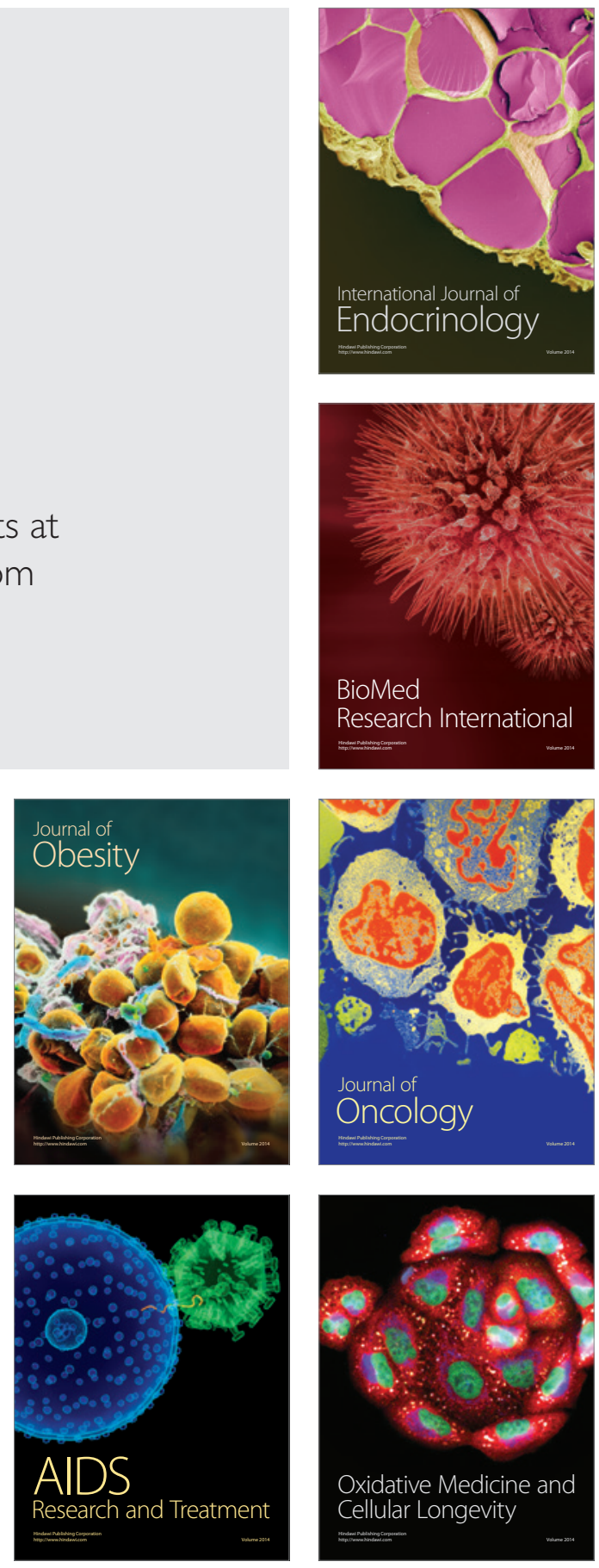